\title{
FUNGITOXIC ACTIVITY OF TWO SESQUITERPENE COMPOUNDS FROM DRECHSLERA CYNODONTIS AGAINST PLANT PATHOGEN FUNGI.
}
Fayzalla, E. A. ${ }^{1}$;
M. E. Abdalla'; Mona

E. A. El-Sherbiny ${ }^{1}$
1- Plant Pathology Department, Faculty of Agriculture, Mansoura University, Egypt

2- Pharmacology Department, Faculty of Pharmacy, Mansoura University, Egypt

\begin{abstract}
Two, sesquiterpenes; Dihydrobipolaroxin (1) and Sorokinianin (2). have been isolated from the culture filtrates of the fungus Drechslera cynodontis. This paper describes the isolation and structure elucidation of the two chemical compounds by EL-MS, 1H-NMR, 13C-NMR, DEPT, COSY, HMQC and HMBC spectra techniques that led to characterization of the two novel compounds; Dihydrobipolaroxin and Sorokinianin. The results obtained for identification of the compound 1 by EL-MS suggesting the molecular formula $\mathrm{C} 18 \mathrm{H} 28 \mathrm{O} 4$. The structure showed consistent with the structure derived by13C-NMR and DEPT spectrum and the structure was confirmed in full agreement with those reported for dihydrobipolaroxin sesquiterpene by Sugawara et al. 1985. The antifungal activity of culture filtrate of Drechslera isolate on the mycelial growth showed significant reduction in mycelial growth and spore germination of all plant pathogens under study. Data showed highly effective growth inhibition against $A$. solani, $F$. oxysporum and $S$. sclerotiorum up to $66.7 \%$, while decreased the other fungal growth by $44.4-51.1 \%$ at concentration of $100 \mu \mathrm{g} / \mathrm{ml}$. Compound 1 caused higher reduction in spore germination of $A$. solani (8\%) and $F$. solani $(77 \%)$ at $100 \mu \mathrm{g} / \mathrm{ml}$ concentration.

For compound (2) The El-MS showed a molecular ion peak $[\mathrm{M}+1]+$ at $\mathrm{m} / \mathrm{z}$ 309 suggesting the molecular formula $\mathrm{C} 18 \mathrm{H} 28 \mathrm{O} 4$. The detailed $1 \mathrm{H}-\mathrm{NMR}$ and $13 \mathrm{C}-$ NMR data were consistent and compound identified as Sorokinianin and in agreement with results reported by Nakajima et al. (1994). Compound 2 (Sorokinianin) decreased the fungal growth at concentration of $100 \mu \mathrm{g} / \mathrm{ml}$ in all tested fungi which ranged from $22.2 \%$ growth inhibition in $R$. solani to $61.1 \%$ in $F$. solani. Compound 2 was highly effective in suppressing spore germination of $F$. solani $(75 \%)$ at $100 \mu \mathrm{g} / \mathrm{ml}$ concentration. Data of experiments done to determine the minimum inhibitory concentrations (MIC) for fungal growth indicated that maximum concentration (100 $\mu \mathrm{g} / \mathrm{ml}$ ) of both compounds was not sufficient for inhibiting completely the growth of all tested fungi. All tested compounds recorded higher MIC values $(>100 \mu \mathrm{g} / \mathrm{ml})$. The MIC for spore germination Compounds 1 and compounds 2 had less inhibitory effect on spore germination of all tested fungi, they recorded- higher MIC values (>100 $\mu \mathrm{g} / \mathrm{ml}$ ).

Keywords: Drechslera cynodontis, sesquiterpenes, antifungal activity, plant pathogenic fungi
\end{abstract}

\section{INTRODUCTION}

Toxins produced by phytopathogenic fungi have assumed great importance because of their involvement in several plant diseases. Most of the plant pathogenic fungi produce toxins in culture and in their hosts. The 
virulence of the plant pathogen may depend on its capability to synthesize one or more toxins. The chemical nature of these toxins ranges from low molecular weight compounds includes all classes of natural products such as terpenes, chromanones, butenolides, pyrones, macrolides, aromatic derivatives, amino acids etc., to high molecular compounds such as proteins, glycoproteins and polysaccharides. In some cases, toxins have been used to obtain products for plant protection or, by genetic selection, plants resistant to specific disease (Heiser et al. 1998). Because phytotoxins are biologically active compounds, various applications employing these metabolites have been attempted. Due to their role in disease development, some phytotoxins have been proposed as potential markers for screening disease resistant plants. Phytotoxins could also be used as potential fungicides and herbicides. Since phytotoxins are toxic not only to crop plants, but also to weeds, herbs, etc. Overall, phytotoxins appear to have an important role in the invasion of the plant tissue, how they are produced, how they interact with the plant defense mechanisms, will bring understanding of the plant-pathogen relationship that would ultimately lead to designing better methods to increase plant resistance against fungal pathogens (Buiatti and Ingram, 1991). The search for new products for the pharmaceutical and agrochemical industries is an on-going process that requires continual optimization. Previously, the screening of 10000 natural products resulted in one commercial products. In the advent of combinatorial chemistry, this relationship changed. Presently, the screening of 100000 structures day from combinatorial chemistry together with the natural products screened yields less than one commercial product year. Its development takes approximately $12 \mathrm{yr}$ and costs $\sim \$ 350 \mathrm{M}$. Considering that 6 out of 20 of the most commonly prescribed medications are of fungal origin and only $~ 5 \%$ of the fungi have been described. Fungi offer an enormous potential for new products (Gloer, 1997). The objectives of this study are: 1) Extraction of fungitoxic metabolites from culture filtrates of Drechslera cynodontis, 2) Effect of isolated compounds on mycelial growth and spore germination of various phytopathogenic fungi, 3) Determination of the minimum inhibitory concentration (MIC) of the active substance's.

\section{MATERIALS AND METHODS}

\section{Drechslera isolate}

An isolate of Drechslera cynodontis (Marignoni) Subram \& B.L. Jain. was obtained from Assiut University Mycological Centre (AUMC), Egypt. The fungus $D$. cynodontis is a natural fungal pathogen on Bermuda grass.

\section{Plant pathogens}

Botrytis fabae, Fusarium oxysporum, Fusarium solani, Rhizoctonia solani, Sclerotinia sclerotiorum and Sclerotium cepivorum were isolated from different crops on potato dextrose agar (PDA) and Czapek agar media. The plates were incubated at $26 \pm 2^{\circ} \mathrm{C}$ or $20 \pm 2^{\circ} \mathrm{C}$ for 7 days. Cultures were purified using single spore or hyphal tip techniques. Pure cultures were identified by mycologists from the Assiut University Mycological Centre 
(AUMC), Egypt. The fungal cultures were maintained on half-strength potato dextrose agar slants in small vials under mineral oil at $4^{\circ} \mathrm{C}$. Fungal strains of Alternaria solani and Botrytis cinerea were obtained from the Plant Pathology Institute, Agricultural Research Center, and Giza, Egypt.

\section{Production of culture filtrates}

For toxin production, small pieces from mycelial mats of 10-day-old cultures of D. cynodontis, grown on PDA Petri dishes, were transferred to 500 $\mathrm{ml}$ flasks containing $200 \mathrm{ml}$ of modified M-1-D medium described by. (Pinkerton and Strobel, 1976) The cultures were incubated under static conditions at $27 \pm 2^{\circ} \mathrm{C}$ in the dark for 4 weeks. The culture fluid was obtained by filtrating through three layers of cheesecloth, and then two layers of the Whatman No.1 filter paper.

Extraction of the metabolites

Culture filtrates of D. cynodontis were concentrated to $10 \%$ of their original volume by using freeze drying. The concentrated filtrate was extracted with chloroform followed by ethyl acetate, then n-butanol using separating funnel ( 3 extractions each using 0.3 volume of organic solvent per volume of filtrate). The chloroform, ethyl acetate and n-butanol extracts were filtered over anhydrous Na2SO4. All the organic fractions separated by solvent extraction were subjected to dryness using rotary evaporator to remove any traces of solvents and to obtain the final residues. The residues were weighed, and collected in vials using methanol. Residues were named as obtained, fraction A (chloroform extract), fraction B (ethyl acetate extract) and fraction $\mathrm{C}$ (butanol extract).

\section{Isolation and purification of metabolites}

Thin layer chromatography (TLC): The chloroform, ethyl acetate and butanol extracts were subjected to thin layer chromatography (TLC) using different solvent systems. The thin layer chromatography sheets used were TLC aluminium sheets, $20 \times 20 \mathrm{~cm}$, silica gel 60, ref: 1.05553., Merck, Darmstadt, Germany, and reverse TLC sheets. Bands on TLC sheets were marked under ultra violet (UV) light (254 and $365 \mathrm{~nm}$ ) or detected by spraying with $5 \% \mathrm{H} 2 \mathrm{SO} 4$ in methanol, followed by heating at $110^{\circ} \mathrm{C}$ for $10 \mathrm{~min}$ till the colours developed.

Preparative TLC: The glass plates of different dimensions were cleaned carefully before use then dried and coated with silica gel GF 254 LR previously slurred with distilled water. The coated plates were left to dry at room temperature then activated in hot-air oven at $100-110^{\circ} \mathrm{C}$ for one hour and immediately transferred to a dessicator to cool and kept until used. The samples were spotted at $1.5 \mathrm{~cm}$ from the lower edge using a capillary tube. The running length for the solvent was from 9.5 to $10 \mathrm{~cm}$. The developed plates were air dried and the metabolite was exposed to either 254 or $365 \mathrm{~nm}$ UV light. Each band was carefully cut off, and each band with silica gel was re-extracted in hot methanol. The solution was further filtered through a 0.2 $\mathrm{mm}$ filter to eliminate the silica gel, then dried by flash evaporator, and weighed. The purified metabolites were used for chemical analysis.

Column Chromatography (CC): Gravitatory columns were used in the first stage of purification and a smaller column in the final stage. All columns were packed with silica gel (Merck, Kieselgel 60, 0.063-0.200 mm, 70-230 mesh 
ASTM, ref: 1.07734.1000, Darmstadt, Germany). The elution of chloroform, ethyl acetate and n-butanol extracts were developed with suitable solvents in the order of increasing polarity.

\section{Identification of bioactive compounds}

Mass Spectra (MS): The Electron Impact Mass Spectra (EI-MS) had a delay of $3 \mathrm{~min}$. to avoid the solvent plead and then scanned from $\mathrm{m} / \mathrm{z} 50$ to $\mathrm{m} / \mathrm{z} 300$. Ionization energy was set at $70 \mathrm{eV}$.

Nuclear Magnetic Resonance (NMR): 1H-NMR and 13C-NMR spectra were recorded at $500 \mathrm{MHz}$ in dimethyl sulfoxide (DMSO). The same solvent was used as internal standard. Carbon multiplicities were determined by Distortionless Enhancement by Polarization Transfer (DEPT). Correlation Spectroscopy (COSY), Heteronuclear Multiple Quantum Coherence (HMQC) and Heteronuclear Multiple Bond Connectivity (HMBC) NMR experiments were performed using Bruker microprograms.

\section{Effects on mycelial growth of different phytopathogenic fungi}

The antifungal activity of pure compounds to tested fungi was investigated using the following mycelial radial growth bioassay. Concentrations were prepared in the range $50-100 \mu \mathrm{g} / \mathrm{ml}$ from pure compounds. The test was carried out by growing each fungal species in Petri dishes containing $20 \mathrm{ml}$ of potato dextrose agar (PDA) amended with concentrations of 50,75 and $100 \mu \mathrm{g} / \mathrm{ml}$ of pure compounds (control plates containing only DMSO). The centre of each PDA plate was inoculated with one fungal disc (5 mm diameter) from edges of fungal solid cultures of the respective fungus. The plates were incubated at $24 \pm 2^{\circ} \mathrm{C}$ for 1-2 weeks, depending on the fungal species. The antifungal activity was evaluated by measuring the diameter of test and control colonies in millimeter. Each assay was repeated at least three times. The percentage of inhibition was calculated on the basis of growth in the control plates using the expression:

$$
\% \text { Mycelial inhibition }=(X-Y / X) \times 100
$$

Where; $X$ and $Y$ are the average diameters of mycelial colonies in control and treated fungi sets.

\section{Effects on spore germination of different phytopathogenic fungi}

The assays were carried out with $A$. solani, $B$. cinerea, $B$. fabae, $F$. oxysporum and $F$. solani, as test fungi. Cultures of the fungi were grown on PDA and/or potato carrot agar (PCA) media for $7-10$ days at $25 \pm 2^{\circ} \mathrm{C}$ until well sporulated except A. solani. The spores were harvested by adding $10 \mathrm{ml}$ of sterile water and aseptically dislodging the spores with a sterile inoculating loop. Spores suspensions were aseptically filtered through sterile cheesecloth to remove mycelial debris. pure compounds were diluted in sterile distilled water to produce twofold serial concentrations 50,75 and $100 \mu \mathrm{g} / \mathrm{ml}$ and $1 \mathrm{ml}$ portions of each concentration were add to test tubes. Spores suspended in distilled water were diluted in potato dextrose broth to produce the inoculum of $1.0 \times 105$ spores $/ \mathrm{ml}$ by using haemocytometer slide. Portions of $1 \mathrm{ml}$ of a particular fungal spore suspension were added to the tubes that contained pure compounds or distilled water (control). These tubes were then incubated at $24 \pm 2^{\circ} \mathrm{C}$ for 24 hours (control tubes containing only DMSO). The 
percentage of spore germination was calculated in 100 spores from 5 microscopic fields. Three tubes were prepared for each treatment and the data was recorded as the mean of three replicates. Sporulation was induced in A. solani by growing it in culture plates of PMDA medium ( $15 \mathrm{~g}$ instant mashed potato mix, $15 \mathrm{~g}$ dextrose, $23 \mathrm{~g}$ agar and $1.5 \mathrm{I}$ water) for 10 to 14 days at room temperature under constant or diurnal light, then cutting the culture medium into 4-cm strips and placing them in $250 \mathrm{ml}$ sterile water in flasks. Vigorously shake the flasks for $1 \mathrm{~min}$, let stand for $10 \mathrm{~min}$, then spread $1.5 \mathrm{ml}$ of the fluid on fresh plates of this medium and incubate under constant fluorescent light at $20^{\circ} \mathrm{C}$ or in diurnal light if above $23^{\circ} \mathrm{C}$. Transferring small block from a 2-day-old PDA colony of A. solani to corn meal agar medium and incubating under light for 4 hours, then in the dark at $18^{\circ} \mathrm{C}$ induces sporulation within 12 hours (Dhingra and Sinclair 1995).

\section{Determination of the Minimum Inhibitory Concentrations (MIC)}

The MIC was determined as the lowest concentration of pure compounds that completely inhibited visible fungal growth. Also, the MIC was determined as the lowest concentration of pure compounds that induced no germination of fungal spores or inhibited $90 \%$ or more of spore germination.

\section{RESULTS}

\section{Extraction procedure:}

Culture filtrates of Drechslera cynodontis were concentrated in a rotary evaporator at $45^{\circ} \mathrm{C}$ to a small volume $(10 \%$ of original volume). Successive extraction was done in a separating funnel with chloroform, ethyl acetate and n-butanol till complete exhaustion. Each fraction was dried over anhydrous sodium sulphate, concentrated in a rotary evaporator, placed in a dessiccator and weighed. Chloroform $(9.5 \mathrm{~g})$, ethyl acetate $(6.5 \mathrm{~g})$ and $\mathrm{n}$ butanol $(15 \mathrm{~g})$, respectively. The residues were kept in a refrigerator for further investigation.

\section{Application of the chloroform extract:}

The chloroform extract of $D$. cynodontis culture filtrates $(9.5 \mathrm{~g})$ was applied as a band to the top of a glass column packed with slurry of silica gel 60 in chloroform. Elution was performed using chloroform, then mixtures of chloroform-methanol with increasing polarity (99:1, 98:2). Fractions of $100 \mathrm{ml}$ were collected. Each fraction was concentrated to $5 \mathrm{ml}$ volume and monitored by TLC on silica gel 60 plates using chloroform-methanol (9.5:0.5 and 9:1) as solvent systems, and vanillin-H2SO4 as spraying reagent. Similar fractions were pooled together, concentrated to dryness, placed in a dessiccator and weighed. The results are recorded in Table (1). 
Fayzalla, E. A. et al.

Table 1: Chromatographic fractionation of the chloroform extract of $D$. cynodontis culture filtrates

\begin{tabular}{|c|cc|c|}
\hline Fraction No. & \multicolumn{2}{|c|}{ Eluent } & \multicolumn{1}{c|}{ Constituent } \\
\hline $1-4$ & $\mathrm{CHCl}_{3}$ & $(100 \%)$ & - \\
\hline $5-14$ & $\mathrm{CHCl}_{3}$ & $(100 \%)$ & one major spot (compound 1) \\
\hline $15-20$ & $\mathrm{CHCl}_{3}-\mathrm{MeOH}(99: 1)$ & - \\
\hline $21-26$ & $\mathrm{CHCl}_{3}-\mathrm{MeOH}(98: 2)$ & one major spot (compound 2) \\
\hline $27-35$ & $\mathrm{CHCl}_{3}-\mathrm{MeOH}(97: 3)$ & - \\
\hline $36-40$ & $\mathrm{CHCl}_{3}-\mathrm{MeOH}(96: 4)$ & - \\
\hline
\end{tabular}

Combined fractions (5-14): Fractions (5-14) were applied as a band to the top of a glass column packed with a slurry of silica gel 60 in $\mathrm{CHCl} 3$. Fractions of $20 \mathrm{ml}$ were collected and monitored by TLC on silica gel 60 plates using $\mathrm{CHCl} 3-\mathrm{MeOH}$ (9.5:0.5 and 9:1) as solvent systems and vanillin-H2SO4 as a spraying reagent. Subfractions 6-8 were pooled together to afford pure compound $1(\mathrm{Rf}$ value $=0.37$ in $\mathrm{CHCl} 3-\mathrm{MeOH} 9: 1)$, which was concentrated to dryness and weighed $(200 \mathrm{mg})$.

Combined fractions (21-26): Fractions (21-26) from the first column were applied as a band to the top of a glass column packed with a slurry of silica gel 60 in $\mathrm{CHCl} 3$. Elution was performed using $\mathrm{CHCl} 3$ then mixtures of $\mathrm{CHCl} 3-\mathrm{MeOH}$ with increasing polarity $(1 \%, 2 \%$ and $3 \%)$. Fractions of $20 \mathrm{ml}$ were collected and monitored by TLC on silica gel 60 plates using the same solvent system and spray reagent previously used. Sub-fractions 3-6 were concentrated and the major component was purified over a preparative TLC using silica gel GF 254 LR, developed in chloroform-methanol (9:1). The band of the major component was located using $254 \mathrm{~nm}$ UV light and scraped with a spatula. The component was extracted from powdered silica in methanol and the solvent evaporated to give a pure compound $2(60 \mathrm{mg})$.

\section{Identification of the isolated compounds}

Compound (1): The El-MS showed a molecular ion peak [M]+ at $\mathrm{m} / \mathrm{z} 264$ and thus suggested the molecular formula $\mathrm{C} 15 \mathrm{H} 20 \mathrm{O} 4$. 13C-NMR (Table 2) and DEPT spectrum confirmed the presence of 2 methyl groups at $\delta C 11.2$ and $23.1 \mathrm{ppm}, 3$ methylene at $\delta C 46.5,61.3$ and $109.8 \mathrm{ppm}, 5$ methine at $\delta C$ $42.3,66.5,123.4,127.9$ and $139.5 \mathrm{ppm}$ and 5 quaternary carbons at $\delta C 36.4$, 76.4, 154.2, 163.6 and $197.5 \mathrm{ppm}$.

The structure was deduced to be bicyclic based on the calculated double bond equivalence $(\mathrm{DBE}=6)$ and the presence of 3 double bonds and one carbonyl carbon. 13C-NMR signal at $\delta 197.5$ confirmed the presence of a keto group. In 13C-NMR spectrum six signals were observed in the olefinic region. Two carbon signals at $\delta C 127.9$ and 139.5 were attributed to $C-1$ and $C-2$ respectively, signals at $\delta C 123.4$ and 163.6 were assigned to $C-9$ and $C$ 10 respectively and the characteristic signals for exomethylene group at $\delta C$ 154.2 and 109.8 were assigned to $\mathrm{C}-11$ and $\mathrm{C}-13$ respectively. Besides, DEPT spectrum confirmed the presence of a primary hydroxyl at $\delta \mathrm{C} 61.3(\mathrm{C}$ 12), a secondary hydroxyl at $\delta C 66.5$ (C-3) and a tertiary hydroxyl at $\delta C 76.4$ (C-7). 1H-NMR and 13C-NMR were in full agreement with those reported for dihydrobipolaroxin sesquiterpene (Sugawara et al. 1985). The structure of 
compound 1 (Dihydrobipolaroxin) was further substantiated by complete assignments of HMBC, HMQC and COSY experiments spectra, which have not been previously reported for it.

Table (2): NMR spectral data of compound 1

\begin{tabular}{|c|c|c|}
\hline Carbon number & ठ 13C-NMR (J HZ) & $\delta 1 \mathrm{H}$ (multiplicity, J HZ) \\
\hline 1 & $127.9 \mathrm{CH}$ & 6.23 br.s. \\
\hline 2 & $139.5 \mathrm{CH}$ & 6.23 br.s. \\
\hline 3 & $66.5 \mathrm{CH}$ & (3.95 d, J=14.4) \\
\hline 4 & $42.3 \mathrm{CH}$ & $1.52 \mathrm{~m}$ \\
\hline 5 & $36.4 \mathrm{C}$ & |----------- \\
\hline 6 & $46.5 \mathrm{CH}_{2}$ & $1.86 \mathrm{~m}$ \\
\hline 7 & $76.4 \mathrm{C}$ & ------------ \\
\hline 8 & $197.5 \mathrm{C}$ & ----------- \\
\hline 9 & $123.4 \mathrm{CH}$ & $5.7 \mathrm{~s}$ \\
\hline 10 & $163.6 \mathrm{C}$ & ----------- \\
\hline 11 & $154.2 \mathrm{C}$ & |--------- \\
\hline 12 & $61.3 \mathrm{CH} 2$ & $3.78 \mathrm{~s}$ \\
\hline 13 & $109.8 \mathrm{CH} 2$ & $5.15 \mathrm{~s} \& 5.18 \mathrm{~s}$ \\
\hline 14 & $23.1 \mathrm{CH} 3$ & $1.32 \mathrm{~s}$ \\
\hline 15 & $11.2 \mathrm{CH} 3$ & $0.93 \mathrm{~s}$ \\
\hline
\end{tabular}

In $\mathrm{HMBC}$ spectrum the proton at $\delta \mathrm{H} 6.23(1 \mathrm{H}$, br.s., $\mathrm{H}-1)$ showed cross peaks with C-3, C-5, C-9 and C-10, the proton at $\delta \mathrm{H} 5.7(1 \mathrm{H}, \mathrm{S}, \mathrm{H}-9)$ showed cross peaks with $\mathrm{C}-5, \mathrm{C}-7$ and $\mathrm{C}-1$. The presence of the exomethylene group in the side chain was confirmed from COSY and HMBC as its two protons at $\delta \mathrm{H} 5.15$ and $5.18 \mathrm{ppm}$ showed cross peaks with the proton at $\delta \mathrm{H} 3.78(2 \mathrm{H}, \mathrm{S}, \mathrm{H}-12)$ (COSY) and with $\mathrm{C}-7, \mathrm{C}-11$ and $\mathrm{C}-12$ (HMBC). EI-MS (Fig. 2), 1H-NMR (Fig. 3), 13C-NMR (Fig. 4), DEPT (Fig. 5), COSY (Fig. 6), HMQC and HMBC spectral analyses concluded the following structure:

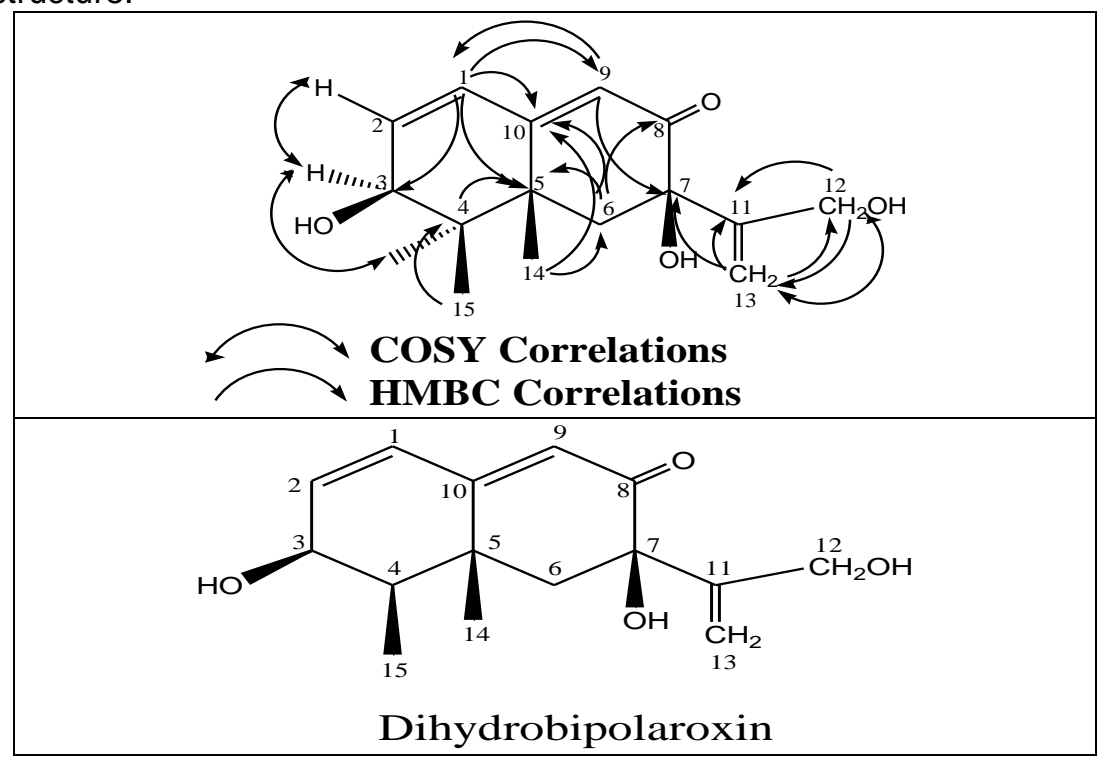

Fig. (1): COSY and HMBC Correlations of compound 1 
Fayzalla, E. A. et al.

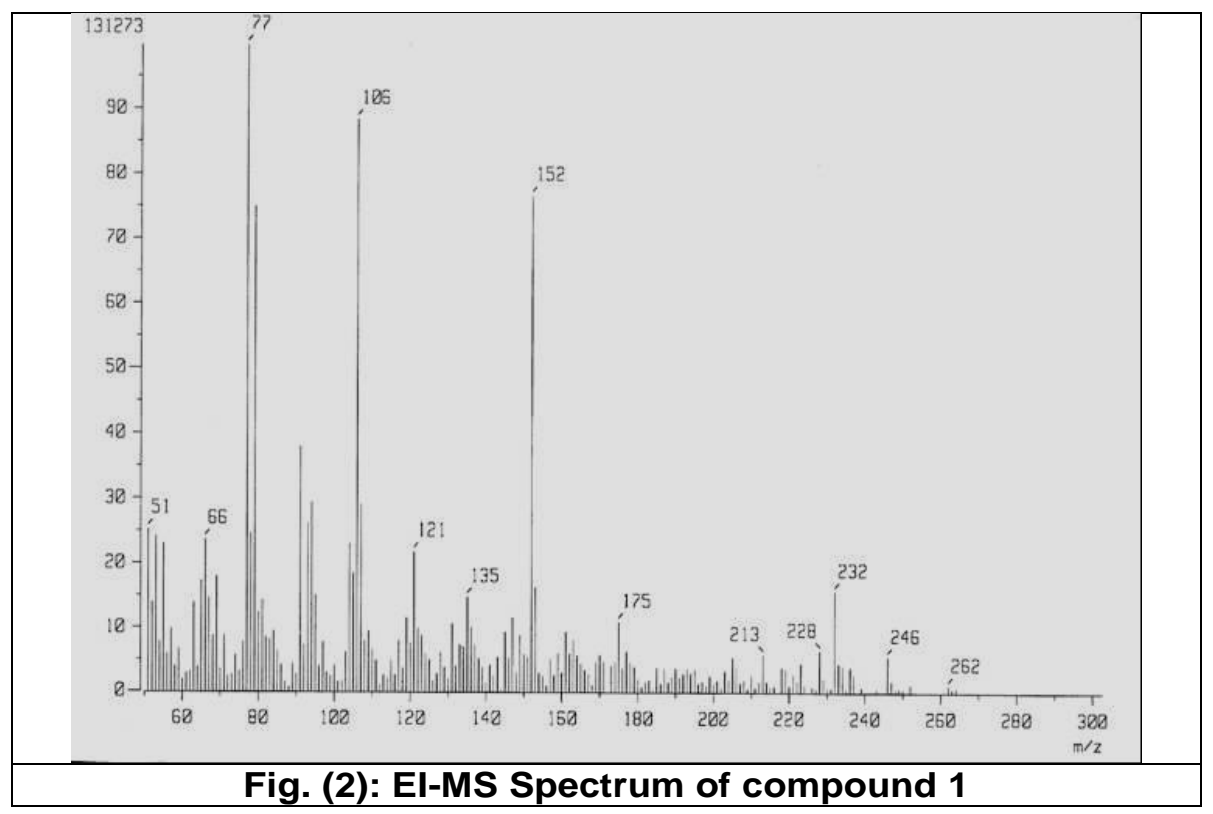

Compound (2): The El-MS showed a molecular ion peak [M+1]+ at $\mathrm{m} / \mathrm{z} 309$ suggesting the molecular formula $\mathrm{C} 18 \mathrm{H} 28 \mathrm{O} 4$. The structure was suggested to be tricyclic based on the calculated double bond equivalence $(\mathrm{DBE}=5)$ and the presence of one double bond and one carbonyl carbon (Table 3).

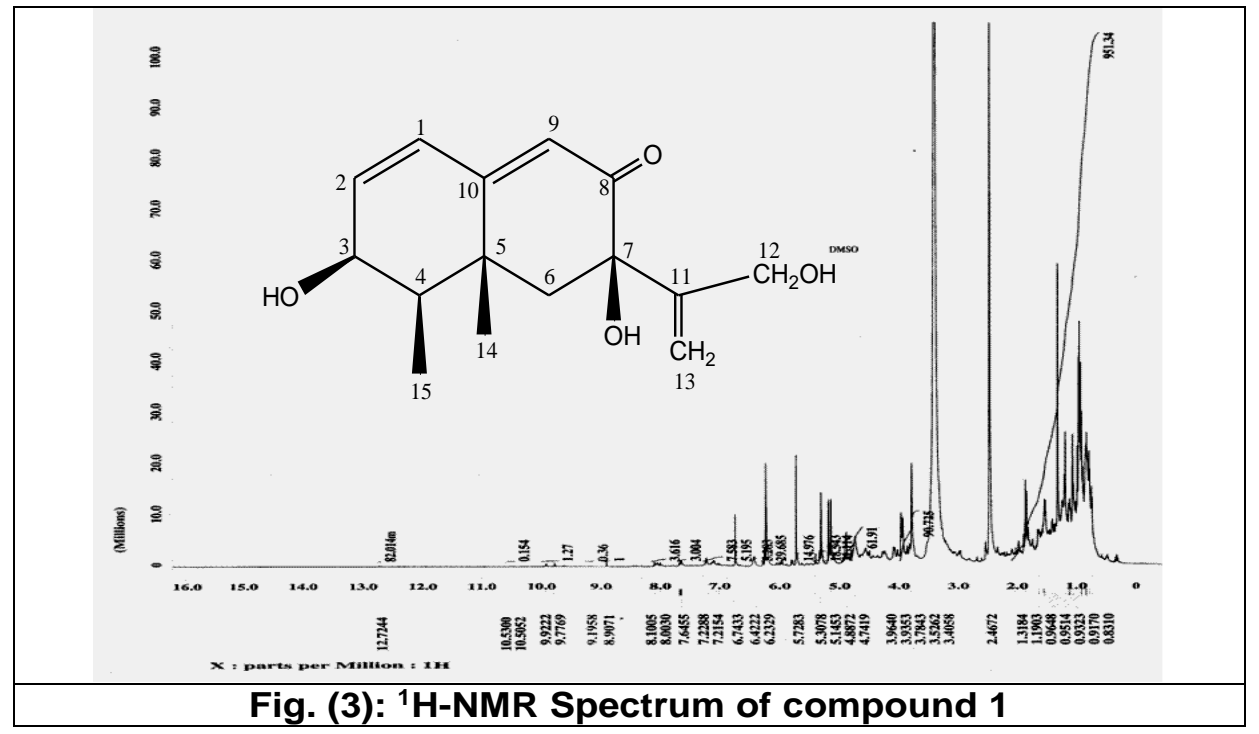




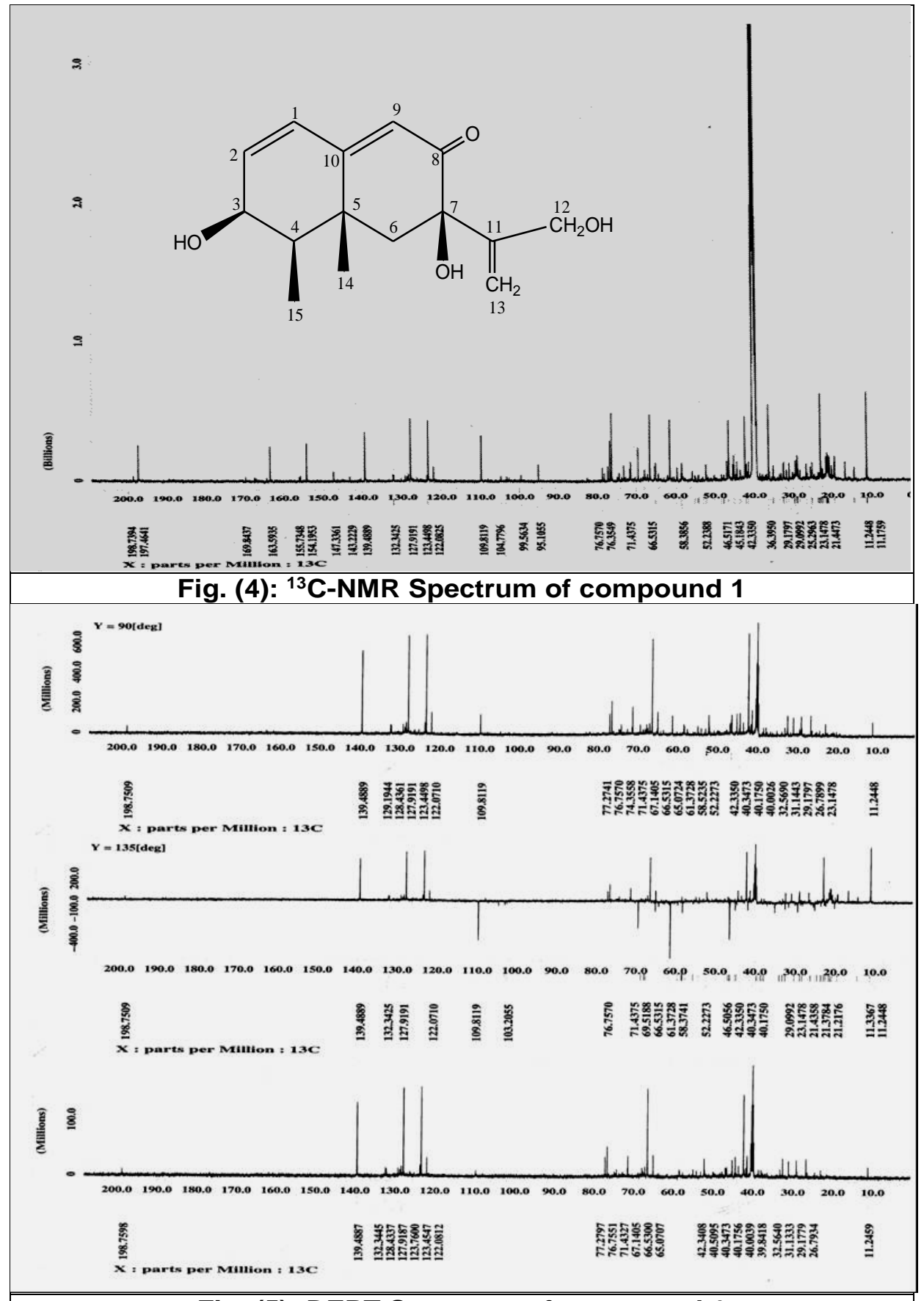

Fig. (5): DEPT Spectrum of compound 1 


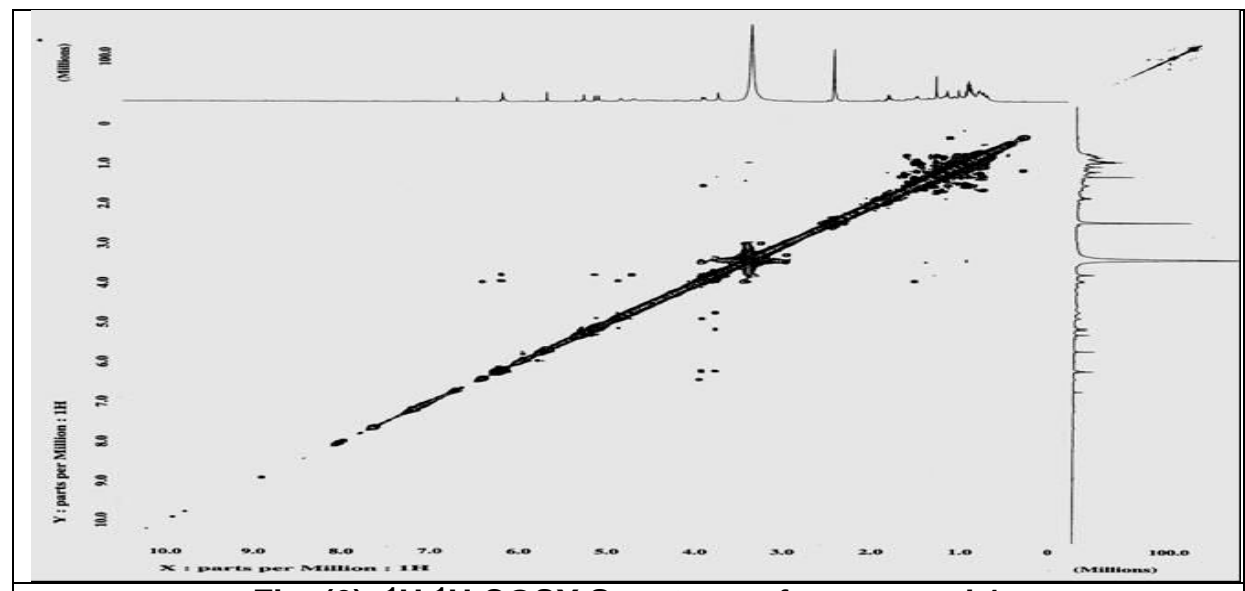

Fig. (6): ${ }^{1} \mathrm{H}-{ }^{1} \mathrm{H}$ COSY Spectrum of compound 1

Table (3): ${ }^{1} \mathrm{H}$ - and ${ }^{13} \mathrm{C}-\mathrm{NMR}$ spectral data of compound 2

\begin{tabular}{|c|c|c|}
\hline Carbon number & ठ 13C-NMR (J HZ) & $\delta 1 \mathrm{H}$ (multiplicity, J HZ) \\
\hline 1 & 48.3 & ---------------- \\
\hline 2 & 44.2 & 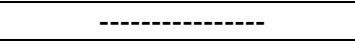 \\
\hline 3 & 24.7 & ---------------- \\
\hline 4 & 49.4 & ---------------- \\
\hline 5 & $39.2 a$ & 2.6 br.s. \\
\hline 6 & 48.3 & ---------------- \\
\hline 7 & 159.2 & -------------- \\
\hline 8 & 59.6 & -------------- \\
\hline 9 & 31.2 & --------------- \\
\hline 10 & $20.6 b$ & $0.77(\mathrm{~d}, \mathrm{~J}=6.9)$ \\
\hline 11 & $20.9 b$ & $0.88(d, J=6.9)$ \\
\hline 12 & 107.3 & $4.78 \mathrm{~s} 5.1 \mathrm{~s}$ \\
\hline 13 & 82.3 & $4.36 \mathrm{ddd}(\mathrm{J}=6.0,6.9,10)$ \\
\hline 14 & 61.5 & ----------------- \\
\hline 15 & 22.1 & $0.91 \mathrm{~s}$ \\
\hline 1 & 37.8 & ------------------ \\
\hline $2^{\backslash}$ & 67.0 & ----------------- \\
\hline $3^{\backslash}$ & 177.1 & ------------------ \\
\hline
\end{tabular}

$$
\text { a - under solvent peak }
$$

b - may be interchanged

An absorption band at $1770 \mathrm{~cm}-1$ (IR spectrum) and a $\mathrm{C}=\mathrm{O}$ signal at $\delta \mathrm{C} 177.1 \mathrm{ppm}$ indicated a $\mathrm{y}$-lactone ring. Besides the characteristic signals for the exomethylene group at $\delta C 159.2$ and 107.3 were assigned to $C-7$ and $\mathrm{C}-12$ respectively. The presence of isopropyl group was confirmed from the two methyl signals at $\delta \mathrm{H} 0.77(3 \mathrm{H}, \mathrm{d}, \mathrm{J}=6.9, \mathrm{H}-10)$ and $\delta \mathrm{H} 0.88(3 \mathrm{H}, \mathrm{d}$, $\mathrm{J}=6.9, \mathrm{H}-11$ ), both have the same $\mathrm{J}$ value i. e. most possibly splitted by the same proton. The detailed 1H-NMR and 13C-NMR data were consistent with those of Sorokinianin (Nakajima et al. 1994). El-MS (Fig. 7), 1H-NMR (Fig. 8) and 13C-NMR (Fig. 9) spectral analyses concluded the following structure: 
J. Agric. Sci. Mansoura Univ., 33 (9): 9633 - , September, 2009
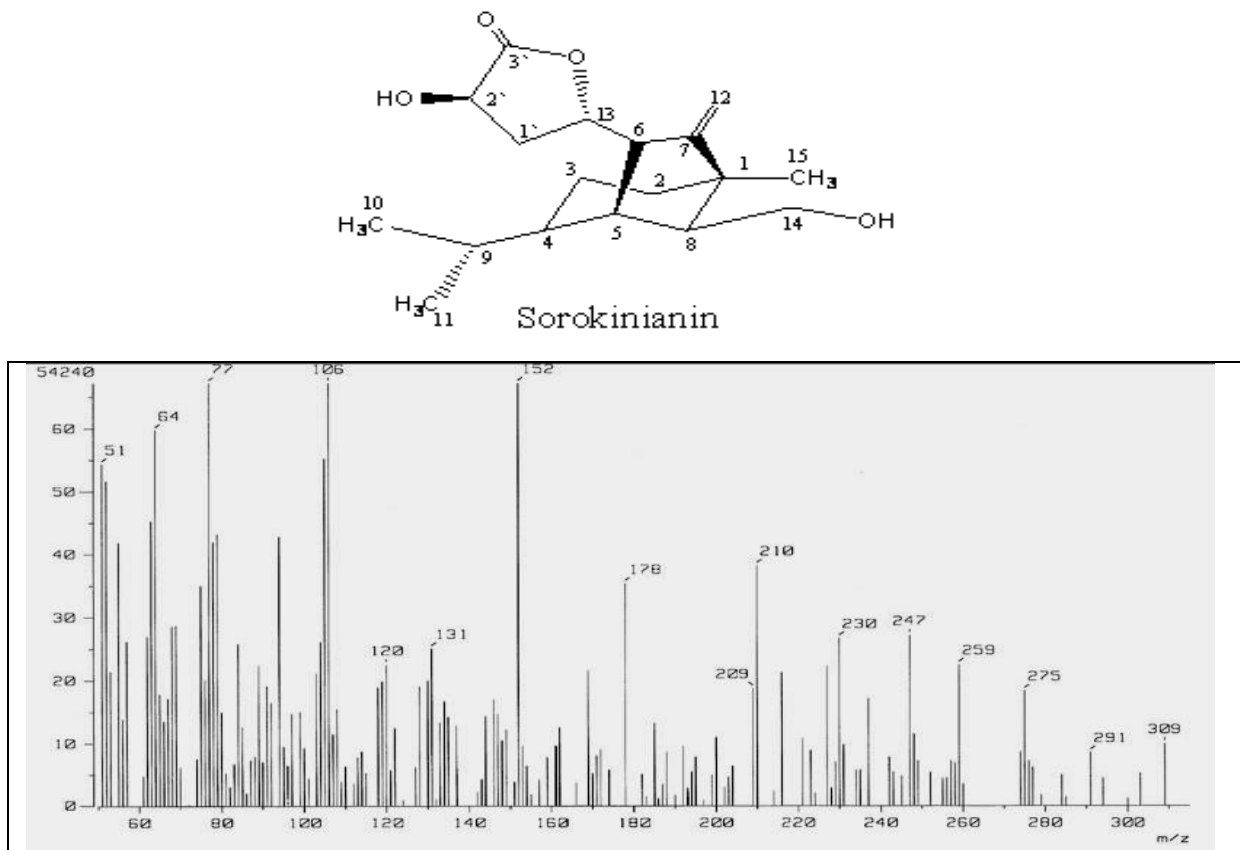

Fig. (7): El-MS Spectrum of compound 2

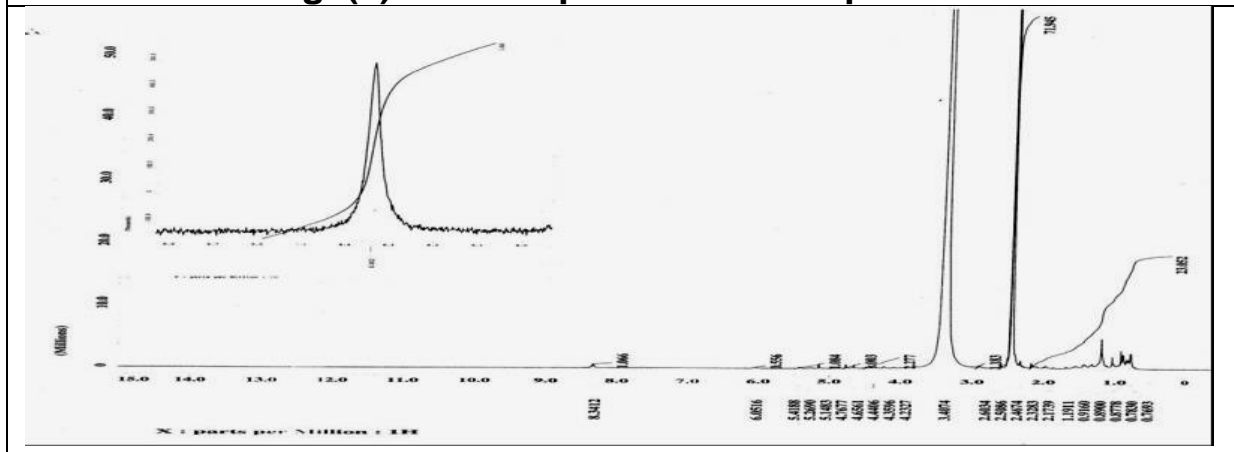

Fig. (8): ${ }^{1} \mathrm{H}-\mathrm{NMR}$ Spectrum of compound 2

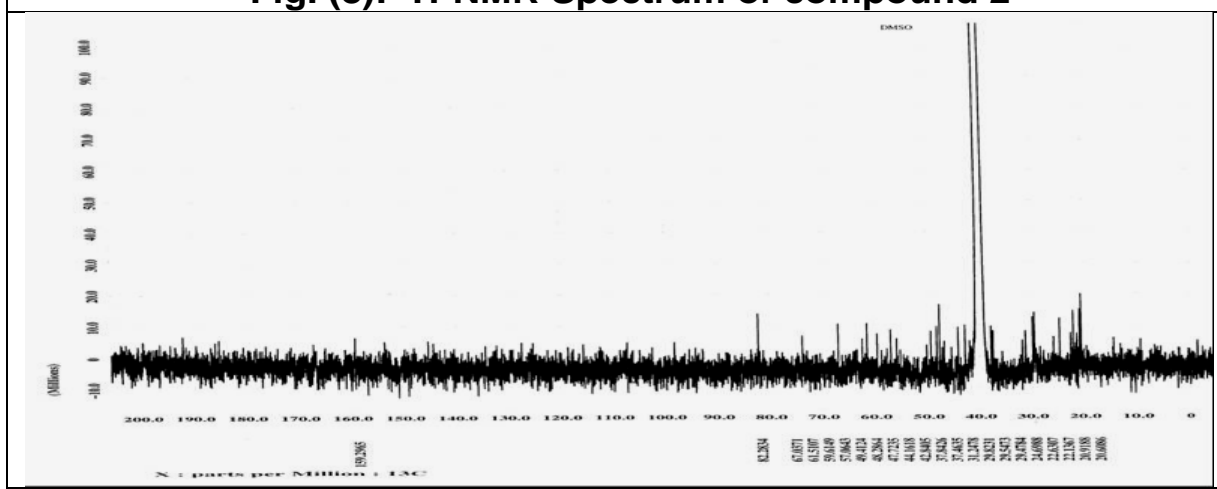

Fig. (9): 13C-NMR Spectrum of compound 2

9733 
Fayzalla, E. A. et al.

Antifungal activity of culture filtrates on the mycelial growth: Data in Tables (4) show that compound 1 (Dihydrobipolaroxin) was highly effective growth inhibitor against $A$. solani, F. oxysporum and S. sclerotiorum $(66.7 \%)$, while decreased the other fungal growth by $44.4-51.1 \%$ at concentration of $100 \mu \mathrm{g} / \mathrm{ml}$. Compound 2 (Sorokinianin) decreased the fungal growth of all tested fungi which ranged from $22.2 \%$ (on $R$. solani) to $61.1 \%$ (on $F$. solani) at concentration of $100 \mu \mathrm{g} / \mathrm{ml}$.

Table (4): Antifungal activity of pure compounds isolated from Drechslera cynodontis on the mycelial growth of tested fungi

\begin{tabular}{|c|c|c|c|c|c|}
\hline \multirow[b]{2}{*}{ Fungi } & \multicolumn{5}{|c|}{ Inhibition of mycelial growth (\%) } \\
\hline & Conc. $\mu \mathrm{g} / \mathrm{ml}$ & Compound 1 & Compound 2 & Control & DMSO \\
\hline \multirow{3}{*}{$\begin{array}{l}\text { Alternaria } \\
\text { solani }\end{array}$} & 50 & 36.7 & 22.2 & 0 & 0 \\
\hline & 75 & 55.6 & 33.3 & 0 & 0 \\
\hline & 100 & 66.7 & 55.6 & 0 & 0 \\
\hline \multirow{3}{*}{$\begin{array}{l}\text { Botrytis } \\
\text { cinerea }\end{array}$} & 50 & 16.7 & 11.1 & 0 & 0 \\
\hline & 75 & 38.9 & 20 & 0 & 0 \\
\hline & 100 & 50 & 44.4 & 0 & 0 \\
\hline \multirow{3}{*}{$\begin{array}{l}\text { Botrytis } \\
\text { fabae }\end{array}$} & 50 & 5.6 & 5.6 & 0 & 0 \\
\hline & 75 & 33.3 & 22.2 & 0 & 0 \\
\hline & 100 & 51.1 & 44.4 & 0 & 0 \\
\hline \multirow{3}{*}{$\begin{array}{l}\text { Fusarium } \\
\text { oxysporum }\end{array}$} & 50 & 11.1 & 11.1 & 0 & 0 \\
\hline & 75 & 33.3 & 20 & 0 & 0 \\
\hline & 100 & 66.7 & 55.6 & 0 & 0 \\
\hline \multirow{3}{*}{ Fusarium solani } & 50 & 16.7 & 20 & 0 & 0 \\
\hline & 75 & 38.9 & 50 & 0 & 0 \\
\hline & 100 & 50 & 61.1 & 0 & 0 \\
\hline \multirow{3}{*}{$\begin{array}{l}\text { Rhizoctonia } \\
\text { solani }\end{array}$} & 50 & 0 & 0 & 0 & 0 \\
\hline & 75 & 44.4 & 11.1 & 0 & 0 \\
\hline & 100 & 44.4 & 22.2 & 0 & 0 \\
\hline \multirow{3}{*}{$\begin{array}{l}\text { Sclerotinia } \\
\text { sclerotiorum }\end{array}$} & 50 & 41.1 & 11.1 & 0 & 0 \\
\hline & 75 & 51.1 & 33.3 & 0 & 0 \\
\hline & 100 & 66.7 & 57.8 & 0 & 0 \\
\hline \multirow{3}{*}{$\begin{array}{l}\text { Sclerotium } \\
\text { cepivorum }\end{array}$} & 50 & 33.3 & 33.3 & 0 & 0 \\
\hline & 75 & 36.7 & 55.6 & 0 & 0 \\
\hline & 100 & 48.9 & 58.9 & 0 & 0 \\
\hline
\end{tabular}

* \% Mycelial inhibition $=(X-Y / X) \times 100$ Where; $X$ and $Y$ are the average diameters of mycelial colonies in control and treated fungi sets. The method of (Dhingra and Sinclair 1995) was used to grow and sporulated fungi

\section{Antifungal activity of culture filtrates of Drechslera isolates on} spore germination

Data in Table (6) show that compound 1 (Dihydrobipolaroxin) highly decreased spore germination of $A$. solani and $F$. solani by 80 and $77 \%$, while it inhibited spore germination of the other fungi by $34 \%$ to $61 \%$ at concentration of $100 \mu \mathrm{g} / \mathrm{ml}$. Compound 2 (Sorokinianin) was highly effective in suppressing spore germination of $F$. solani $(75 \%)$ at conc. $100 \mu \mathrm{g} / \mathrm{ml}$, while it inhibited the spore germination of the other four fungi by $43 \%$ to $60 \%$. 
Table (5): Antifungal activity of pure compounds isolated from Drechslera cynodontis on spore germination of tested fungi

\begin{tabular}{|c|c|c|c|c|c|}
\hline \multirow[b]{2}{*}{ Fungi } & \multirow[b]{2}{*}{ Conc. $\mu \mathrm{g} / \mathrm{ml}$} & \multicolumn{4}{|c|}{ Inhibition of spore germination (\%) ${ }^{\star}$} \\
\hline & & Compound 1 & Compound 2 & Control & DMSO \\
\hline \multirow{3}{*}{$\begin{array}{l}\text { Alternaria } \\
\text { solani }\end{array}$} & 50 & 60 & 20 & 0 & 0 \\
\hline & 75 & 75 & 30 & 0 & 0 \\
\hline & 100 & 80 & 60 & 0 & 0 \\
\hline \multirow{3}{*}{$\begin{array}{l}\text { Botrytis } \\
\text { cinerea }\end{array}$} & 50 & 19 & 26 & 0 & 0 \\
\hline & 75 & 21 & 45 & 0 & 0 \\
\hline & 100 & 34 & 59 & 0 & 0 \\
\hline \multirow{3}{*}{$\begin{array}{l}\text { Botrytis } \\
\text { fabae }\end{array}$} & 50 & 28 & 40 & 0 & 0 \\
\hline & 75 & 49 & 40 & 0 & 0 \\
\hline & 100 & 61 & 50 & 0 & 0 \\
\hline \multirow{3}{*}{$\begin{array}{l}\text { Fusarium } \\
\text { oxysporum }\end{array}$} & 50 & 10 & 11 & 0 & 0 \\
\hline & 75 & 23 & 27 & 0 & 0 \\
\hline & 100 & 56 & 43 & 0 & 0 \\
\hline \multirow{4}{*}{$\begin{array}{l}\text { Fusarium } \\
\text { solani }\end{array}$} & 50 & 50 & 50 & 0 & 0 \\
\hline & 75 & 61 & 60 & 0 & 0 \\
\hline & 100 & 77 & 75 & 0 & 0 \\
\hline & 50 & 60 & 20 & 0 & 0 \\
\hline
\end{tabular}

* The percentage of spore germination was calculated in 100 spores from 5 microscopic fields using haemocytometer slide

Determination of the minimum inhibitory concentrations (MIC)

The MIC for fungal growth: Data in Table (5) show that the maximum concentration $(100 \mu \mathrm{g} / \mathrm{ml})$ of any compounds was not sufficient for inhibiting completely the growth of tested fungi. All tested compounds recorded higher MIC values $(>100 \mu \mathrm{g} / \mathrm{ml})$.

The MIC for spore germination: Compounds 1 and compounds 2 had less inhibitory effect on spore germination of all tested fungi, they recorded higher MIC values $(>100 \mu \mathrm{g} / \mathrm{ml})$.

Table (6): Effect of MIC* of pure compounds from D.cynodontis on the mycelia growth and spore germination of the tested fungi

\begin{tabular}{|l|c|c|}
\hline Compound & Compound 1 & Compound 2 \\
\hline Alternaria solani & $>100^{* *}$ & $>100$ \\
\hline Botrytis cinerea & $>100$ & $>100$ \\
\hline Botrytis fabae & $>100$ & $>100$ \\
\hline Fusarium oxysporum & $>100$ & $>100$ \\
\hline Fusarium solani & $>100$ & $>100$ \\
\hline Rhizoctonia solani & $>100$ & $>100$ \\
\hline Rhizoctonia solani & $>100$ & $>100$ \\
\hline Sclerotium cepivorum & $>100$ & \\
\hline
\end{tabular}

${ }^{\star}$ MIC =minimum inhibitory concentrations ${ }^{\star *}$ Concentration $100 \mu \mathrm{g} / \mathrm{ml}$.

\section{DISCUSSION}

Two compounds (dihydrobipolaroxin and sorokinianin) isolated from culture filtrates of the fungus $D$. cynodontis. This is the first report of separation of dihydrobipolaroxin from this fungus. It was separated before from Bipolaris cynodontis (Sugawara et al. 1985). This is the first time to carryout the 2D-NMR experiments (HMBC, HMQC and COSY) for this compound. Also, this is the first report of isolation of sorokinianin from $D$. cynodontis. It was isolated before from Bipolaris sorokiniana (Nakajima et al. 
1994). Dihydrobipolaroxin and sorokinianin belong to sesquiterpenes. The sesquiterpenes are a large family of C15-isoprene natural products found in higher and lower plants, microbes and some marine organisms. Approximately 5000 sesquiterpenes have been reported. Mono-, bi-, tricyclic sesquiterpenes are all common in plants and fungi. Many have biological activity, including antimicrobial, antitumor, and cytotoxic properties. In plants, they play important ecological roles in interactions with insects and microbes and act as attractants, deterrents, antifeedants and phytoalexins. Sesquiterpenes are key components of many essential oils, which are important commercially for the flavour and fragrance industries. Sesquiterpenes from fungal pathogens are sometimes active as phytotoxins, i. e., compounds that break down host tissues and release nutrients for the pathogens (Fraga 1999).

Sesquiterpenes belong to the largest class of natural products, terpenes (also known as terpenoids or isoprenoids). Of the approximately 25,000 terpene structures reported, very few have been investigated from a functional perspective. All the two compounds were tested for inhibitory activity against some phytopathogenic fungi. Compound 1 (Dihydrobipolaroxin) was highly effective growth inhibitor against $A$. solani, $F$. oxysporum and S. sclerotiorum (66.7\%), while compound 2 (Sorokinianin) decreased the fungal growth of all tested fungi which ranged from $22.2 \%$ (on R. solani) to $61.1 \%$ (on F. solani) at concentration of $100 \mu \mathrm{g} / \mathrm{ml}$. Compound 1 highly decreased spore germination of $A$. solani and $F$. solani by 80 and $77 \%$, while compound 2 was highly effective in suppressing spore germination of $F$. solani $(75 \%$ ) at concentration of $100 \mu \mathrm{g} / \mathrm{ml}$,(inhibiting the spore germination of other fungi by $43 \%$ to $60 \%$ ).

Species of Bipolaris, Drechslera, Exserohilum, and Curvularia constitute a group of taxonomically related and ecologically similar deuteromycetes (mitosporic fungi) that are important plant pathogens or common saprophytes throughout the world. The first three of these genera were segregated from Helminthosporium in several revisions from 1930 to 1974, and some species of Bipolaris and Curvularia share the same teleomorph (Pratt 2006). The generic name Bipolaris for the Helminthosporium species with fusoid, straight, or curved conidia germinating by one germ tube from each end (bipolar germination). (The former genus Helminthosporium was divided into three anamorphic genera: Bipolaris, Drechslera, and Exserohilum with the teleomorphic stages Cochliobolus, Pyrenophora, and Setosphaeria, respectively.) B. sorokiniana is characterized by thick-walled, elliptical conidia $(60-120 \mu \mathrm{m} \times 12-20 \mu \mathrm{m})$ with five to nine cells. In axenic culture, the mycelium is composed of hyphae interwoven as a loose cottony mass and appears white or light to dark grey depending on the isolates. The fungus is differentiated from other members of the Bipolaris genus on the basis of morphological features of conidiophores and conidiospores (Kumar et al., 2002).

The inability of microorganisms to produce large amounts of a toxin or the high costs of purification, represent potential constraints to their practical use as natural pesticides. Their chemical syntheses or the chemical 
synthesis of the active moiety could overcome those limitations. Unfortunately, the natural compounds often have very unusual and complex structures, and by synthesis only very partial structures can be achieved. Several fungal pathogens, especially those belonging to the genera Drechslera, Alternaria and Cochliobolus produce phytotoxins that are virulence and/or pathogenicity factors. These compounds are active against the same plant species as the fungal pathogens and low (physiological) concentrations of the toxin are able to reproduce symptoms of the natural infections. These plant-specific metabolites have received attention as models for new herbicides. There are many reasons why natural products might be good sources of molecules or molecular templates for pesticides or at least lead to new targets of action (Rimando and Duke 2006). New mechanisms of action for pesticides are highly desirable to fight the evolution of resistance in the target pests, to create or exploit unique market niches, and to cope with new regulatory legislation. Comparatively little effort has been expended on determination of the sites of action of phytotoxins from natural sources, suggesting that intensive study of these molecules will reveal many more novel mechanisms of action (Duke et al., 2000). Correlations of structure-activity are of utmost importance to the knowledge of the structural characteristics of the fungal metabolites and the determination of their active sites, or to hypothesize their chemical transformation to obtain more active, stable or selective compounds.

\section{REFERENCES}

Buiatti M. and Ingram D. S. (1991). Phytotoxins as tools in breeding and selection of disease-resistant plants. Experientia 47: 811-819.

Dhingra, O. D. and Sinclair J. B. (1995). Basic plant pathology methods. 2nd ed. Boca Raton, FI: CRC Press.

Duke S. O., Romagni J. G. and Dayan E. F. (2000). Natural products as sources for new mechanisms of herbicidal action. Crop Protection 19: 583-589.

Fraga B. M. (1999). Natural sesquiterpenoids. Nat. Prod. Rep. 16: 711-730.

Gloer J. B. (1997). Application of fungal ecology in the search for new bioactive natural products. In The Mycota. Vol. IV. Environmental and Microbial Relationships (Wicklow D. T. and Soderstrom B. E., Eds.), pp 249-268. Springer-Verlag. New York. USA.

Heiser I., Obwald W. and Elstner E. F. (1998). The formation of reactive oxygen species by fungal and bacterial phytotoxins. Plant Physiol. Biochem. 36: 703-713.

Kumar J., Schafer P., Ralph H., Langen G., Baltruschat H., Stein E., Nagarajan S. and Kogel K. (2002). Bipolaris sorokiniana, a cereal pathogen of global concern: cytological and molecular approaches towards better control. Molecular Plant Pathology 3: 185-195.

Nakajima H., Isomi K. and Hamasaki T. (1994). Sorokinianin: a novel phytotoxin produced by the phytopathogenic fungus Bipolaris sorokiniana. Tetrahedron Letters 35: 9597-9600. 
Fayzalla, E. A. et al.

Pinkerton, F. and G.A. Strobel (1976). Serinol as an activator of toxin production in attenuated cultures of $H$. sacchari. Proc. Natl. Aca. Sci. (USA) 73:4007- 4011.

Pratt R. G. (2006). Enhancement of sporulation in species of Bipolaris, Curvularia, Drechslera, and Exserohilum by growth on cellulosecontaining substrates. Mycopathologia 162: 133-140.

Rimando A. M. and Duke S. O. (2006). Natural products for pest management In: Rimando A. and Duke S. (Eds.), Natural Products for Pest Management. ACS Press, Washington DC, pp. 2-21.

Sugawara F., Strobel G. A., Fisher L. E., Van Duyne G. D. and Clardy J. (1985). Bipolaroxin, a selective phytotoxin produced by Bipolaris cynodontis. Proc. Natl. Acad. Sci. USA 82: 8291-8294. 
تأثثر النشاط المضاد للفطريات لمركبين من مركبات السيسكوتربينات معزولين من

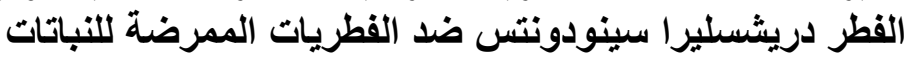

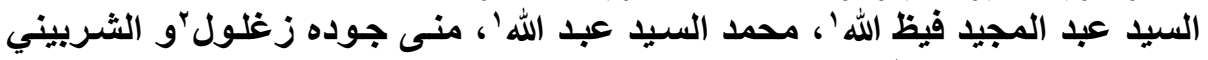

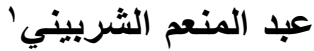

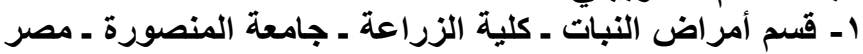

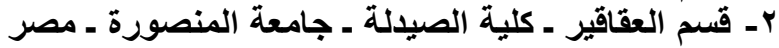

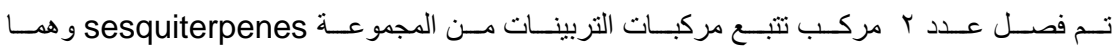

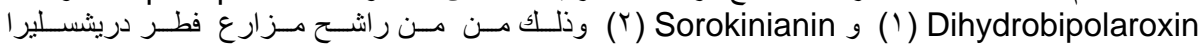

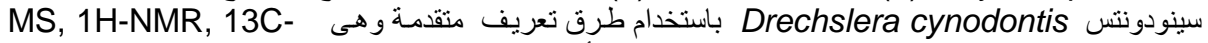
NMR, DEPT, COSY, HMQC, HMBC

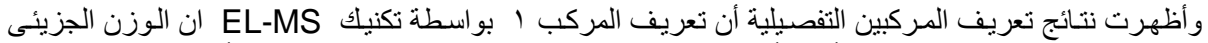

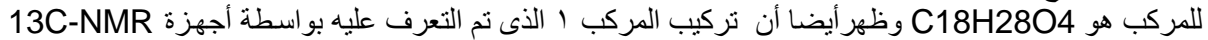

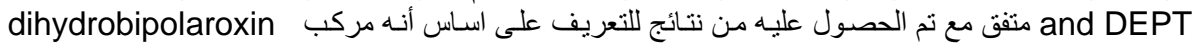
Sesquiterpene

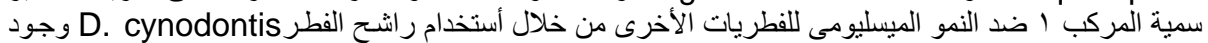

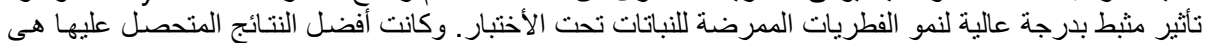

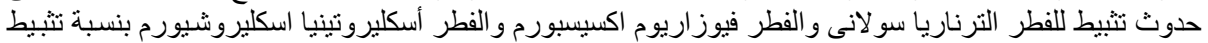

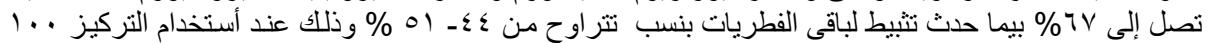

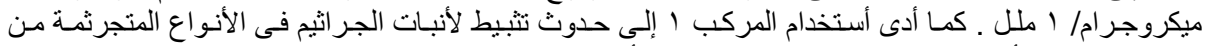

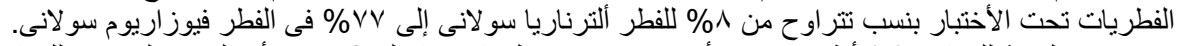

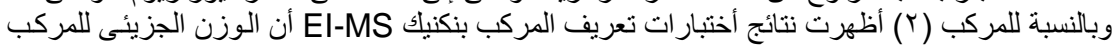

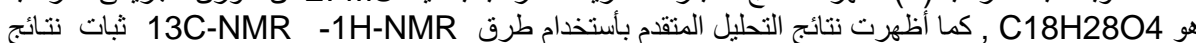
التعريف الأولية وتطابقها وأن المركب عبارة عن Sorokinianin وذلك في تطابق مع مـا تحصل عليه باحثين

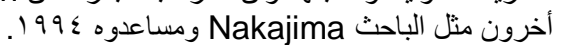

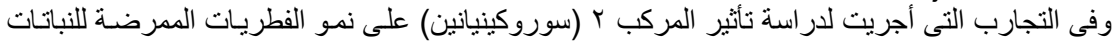

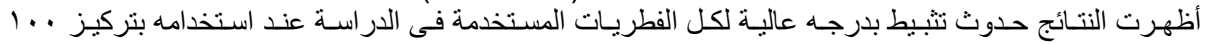

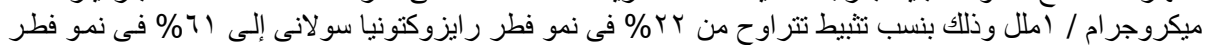

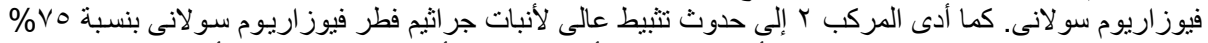

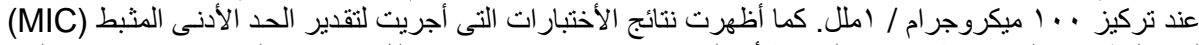

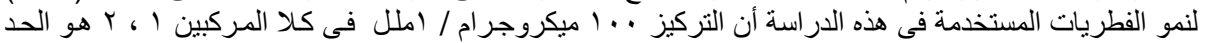

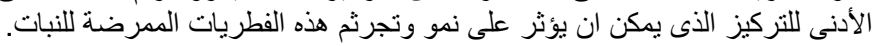

